\title{
Narratividade, memorável e perspectivação na carta do escravo Felício
}

\author{
Narrativité, mémorable et perspectivation dans la lettre de l'Esclave Felício
}

\author{
Soeli Maria Schreiber da Silva ${ }^{1}$ \\ Universidade Federal de São Carlos
}

\begin{abstract}
- RESUMO: Este artigo foi apresentado numa primeira versão em evento em homenagem à Eni Orlandi, na UEMS-MS.É parte do trabalho desenvolvido sobre argumentação, no projeto FAPESP 2015/16397-2. Proponho-me a analisar a Carta do Escravizado Felício, a partir do conceito de Narratividade (ORLANDI, 2014), apoiando-me no conceito de memorável de Guimarães (2002), trago a nomenclatura Al-x de Guimarães(2002,2017) e o conceito de perspectivação de Dias(2012,2013,2015).Vou trabalhar num diálogo entre a abordagem enunciativa e discursiva, mostrando como Al-x diz a escravidão numa narratividade na qual os memoráveis têm a ver com a identidade desse espaço. Analiso também a perspectivação na orientação argumentativa.

- PALAVRAS-CHAVE: Narratividade. Enunciação. Perspectivação.

- RÉSUMÉ: Cet article a été presenté dans une première version à un évènement en hommage à Eni Orlandi, à 1' UEMS-MS. C'est une partie du travail developpé sur l'argumentation, dans le projet FAPESP 2015/16397-2. Je me propose d'analyser la lettre de l'Ex-esclave Felício, a partir du concepte de Narrativité (ORLANDI, 2004), en m'appuiyant sur le concepte de Mémorable de Guimarães (2002), j'apporte la nomenclature Al-x de Guimarães (2017) et le concepte de perspectivation de Dias (2012,2013,2015). Je travaillerai dans un dialogue entre l'abordage énonciative et discursive, montrant commment Al-x dit l'esclavage dans une narrativité dans laquelle les memorables ont un lien avec l'identité de cet espace. J'analyse aussi la perspectivation dans l'orientation argumentative.
\end{abstract}

- MOTS-CLÉS: Narrativité. Enonciation. Perspectivation.

\section{Narratividade, Memorável e Perspectivação}

Este artigo foi apresentado numa primeira versão em evento na UEMS-MS, em homenagem à Eni Orlandi. É parte do projeto FAPESPN ${ }^{0} 2015$ /16397-2, desenvolvido sobre o tema de argumentação, que aqui será tratada como perspectivação.

Neste texto vamos analisar a narratividade considerando Orlandi (2014), os memoráveis (GUIMARÃES 2002) e a perspectivação (DIAS, 2012,2013,) a partir de uma teoria semântica enunciativa, na carta do ex-escravo Felício, texto que pertence ao acervo da Fazenda Conde do Pinhal. Esta carta foi escrita em 1917 e é dirigida ao senhor Antônio Carlos Botelho, filho do Conde do Pinhal, fundador da cidade de São Carlos. Os estudos de Orlandi sobre a narratividade tratam da maneira como a memória se diz nos processos identitários e os modos de individualização textualizados na narratividade. Aautora diz:

propomos pensar a narratividade como a maneira pela qual uma memória se diz em processos identitários apoiados em modos de individuação do sujeito, afirmando/vinculando (seu 'pertencimento') sua existência a espaços de interpretação determinados, consoantes a. (ORLANDI, 2014, p. 79.)

\footnotetext{
${ }^{1}$ Doutora em Linguística pela UNICAMP.xoila@terra.com.br
} 
Nesse sentido a memória da escravização em São Carlos, tratada aqui como memoráveis, por serem relações entre enunciações, está textualizada no processo discursivo da carta, que o acervo nomeia como Carta do Escravo Felício. Gostaria de dizer como o fez Guimarães (2002) que os falantes, são sujeitos da língua enquanto constituídos por este espaço de línguas e falantes que chamo espaço de enunciação (GUIMARÃES, 2002, p.18). Este falante está identificado por uma divisão das línguas, a partir do conceito de político de Guimarães (2002) E é nessa divisão que o falante Felício vai falar como escravo e como ex escravo alfabetizado, escrevendo a carta ao Ilustríssimo SrAntonio Carlos Botelho, como ele mesmo diz.

Em Orlandi (2001), a autora fala em "flagrantes da cidade" (ORLANDI, 2001, p. 10) como modo de visualizar o lugar em que o "simbólico e o político se articulam na produção de sentidos" (ORLANDI, 2001, p. 10). Nessa carta há uma demanda que nos faz observaraté que ponto a carta tem a ver com a identidade do espaço e em que medida se diz a cidade de São Carlos. Vejamos:

(a) a fazenda a seu avo deixou no testamento os cocaios (para) se elle morrer para por a capela de senhor São Carlos nos cocais dahi a 6mezelle morreu ahi seu avô tratou logo disso fui eu elle mastrez rapazes cheguem lá na rua São Carlos mandou pica e fincou trez estaca e foi embora quando foi 12 horas estava acabado a picada elle pareceu lá ahimedimo deu dousalquiere de matta rocemos queimos destoquemos. (CARTA DO ESCRAVO FELÍCIO, ID 3014 DA FAZENDA CONDE DO PINHAL,1917, p.4).

O recorte (a) é uma narratividade que se desenvolve integrando enunciados(GUIMARÃES, 2011, p.20) e nessa relação de integração, temos um falante agenciado do lugar social de ex-escravo alfabetizado. Na teoria da Semântica do Acontecimento (GUIMARÃES, 2002) o modo de analisar a cena enunciativa na relação com a exterioridade é um processo de interpretação dos memoráveis recortados. A narratividade desenvolve-se a partir do testamento deixado pelo Conde do Pinhal para construir a capela do senhor São Carlos nos cocais. Do lugar social de al-x- ${ }^{2}$ ex escravo alfabetizado, apresenta uma enumeração que projeta os fundamentos da Catedral de São Carlos, numa terra deixada pelo Conde do Pinhal: Esse sujeito na tomada da palavra, enquanto falante alfabetizado é tomado pelo espaço de enunciação de escravizado.

Esse flagra textualizado numa carta ressignifica o lugar social de escravo escravizado na medida em que o espaço de enunciação da escravização é projetado pelo alocutor-x da carta, ex-escravo alfabetizado. No acontecimento da carta o al-x projeta-se sobre o escravo-escravizado recortando memoráveis da escravização do passado. Nesse lugar, diria Orlandi, "sujeito e sentido filiam-se a uma memória, se inscrevem na discursividade, ou seja, nos efeitos materiais da inscrição da falha da língua na história" (ORLANDI, 2014, p. 75).

O (al-x)-ex-escravo-alfabetizado, ancorado na escrita, sitia gestos de interpretação presentificando os memoráveis recortados no espaço de enunciação da atualidade, na condição de liberto.Aqui o ex-escravo formula seu dizer deslocando o título da carta no acervo da Fazenda Conde do Pinhal para a carta de Ex-Escravo Felício e temos uma outra identificação dada desse lugar.

Assim, vejo o (al-x) ex-escravo gerindo o apagamento da escravização nesse gesto que vai interpretando-a discursivamente na relação entre os memoráveis epertinência enunciativa. $\mathrm{O}$ espaço enunciativo da escravização é ressignificado pelo

\footnotetext{
${ }^{2}$ Utilizo aqui a nomenclatura de Guimarães 2017 para lugar social do Locutor- Al-x
} 
ex-escravoque agora significa um gesto simbólico da escravização em São Carlos para deslocá-la como um movimento de resistência. Isso se dá pela perspectivação. Nesse espaço de enunciação de liberto, o ex-escravo textualiza o fundamento da Catedral de São Carlos, em terras doadas pelos escravistas.

Localizo esse conceito. Para Dias (2013) "a significação constitui-se na relação entre memória e atualidade" (DIAS, 2013, p. 391). Com esse conceito a relação com a memória da escravização significa ao trazer a memória na instância do presente para ressignificá-la. Assim o modo de ressignificar a escravização convoca o passado numa pertinência enunciativa, que instala o motivo do enunciável. Aí opera também o conceito de perspectivação, onde se dará a orientação do enunciável.

O funcionamento da perspectivação numa Formação Nominal, na qual "a articulação entre o núcleo e os determinantes é explicada não em função depropriedades, mas em função das condições enunciativas que dão suporte a um domínio referencial" (DIAS, 2013, p.21), pode ser observado em:

(b) Segue o santo retrato de seu avô, que o senhor me pedio para mandar. (CARTA DO ESCRAVO FELÍCIO: ID3014 DO ACERVO DA FAZENDA CONDE DO PINHAL).

Na Formação Nominal (FN)santo retrato qual é a pertinência enunciativa desse dizer na relação com a atualidade do retrato enviado? Santo converge para o substantivo retrato sob a forma de uma perspectivação, isto é, um modo de conceber retrato. $\mathrm{O}$ enunciável articula a memória à atualidade na perspectivação que orienta santo determinando retrato e não casal.

Assim o lugar social de dizer (al-x) ex-escravo-alfabetizado, da Fazenda Conde do Pinhal, instala uma santidade do retrato havendo uma distinção para o retrato. E também o verbo pedio expõe uma pertinência enunciativa, que projeta o lugar do (al$x)$ ex-escravo-alfabetizado na medida em que pedio é diferente na relação com o alocutário. Assim passa-se de um referencial de ordem para um referencial de pedido.

A carta que vimos analisando é um gesto de resposta numa discursividade na qual há uma inscrição do ex-escravo e nessa inscrição o sujeito se significa como podemos ver em:

(c) Eu estimava esse cazar como se fosse pae e mae, eu Deus que perdoe algum erro delle e della que tenha sua alma na Gloria. (ACERVO DA FAZENDA CONDE DO PINHAL ID 3014 CARTA DO ESCRAVO FELÍCIO, p.1)

Em (c),no referencial afetivo de estima e o referencial familiar, na relação A como se B, não temos uma relação de identidade em A e B (SCHREIBER da Silva,1999). O referencial familiar especifica o referencial de estima e essa especificação estabelece uma relação com o memorável na medida em que se projeta no passado a pertinência de criticá-lo. Essa é a perspectivação.O verbo estimar no passado também instala a perspectivação que estabelece a relação com o passado.

O (al-x)ex-escravo-alfabetizado afirma o pertencimento à escravização e anarratividade se integra a um referencial religioso, pedindo perdão à Deus para o casal ter sua alma na glória. O (al-x)ex-escravo-alfabetizado inscreve-se na divisão escravização e poder da religião para salvar a alma dos escravizadores, rememora o passado na perspectivação de semelhança entre os referenciais de $\mathrm{A}$ e $\mathrm{B}$, para a atualização no referencial religioso no pedido pelos erros dos escravizadores para que tenham sua alma na glória. Há uma deriva de sentidos que se materializam pelos 
diferentes referenciais históricos. Nessa deriva o (al-x)ex-escravo-alfabetizado ancorado nos memoráveis, diz-se enquanto (al-x) escravo e (al-x)ex-escravo-alfabetizado. Então a pertinência da memória é captada nessa deriva dos referenciais na perspectivação de um pedido de perdão para os escravizadoresirem para o céu ou serem salvos, e também para (al-x)-distanciar-se da escravização.

Vejamos agora os recortes (d),(e),(f) :

(d) Eu quando tinha 14 annos ele achou suficiente pra ser feitor eu chorei no pez delle que não queria ser feitor mas ele disse que escravo faz o que a senhoria manda.(ACERVO DA FAZENDA CONDE DO PINHA.CARTA DO ESCRAVO FELÍCIO ID 3014, p.3)

(e) Dahi a cinco mez e comprou 6 escravo a 11 mez comprou 16 escravo 12 dahi a doze mez 28 escravo.(ACERVO DA FAZENDA CONDE DO PINHAL.CARTA DO ESCRAVO FELÍCIO ID 3014, p.3)

(f) a fazenda seu avo deixou no testamento os cocaios (para) se elle morrer para por a capela de senhor São Carlos no cocais dahi a 6mezelle morreu ahi seu avô tratou logo disso fui eu elle mastrez rapazes cheguem lá na rua São Carlos mandou pica e fincou trez estaca e foi embora quando foi 12 horas estava acabado a picada elle pareceu lá ahimedimo deu dousalquiere de matta rocemos queimos destoquemos.(ACERVO DA FAZENDA CONDE DO PINHAL. CARTA DO ESCRAVO FELÍCIO ID 3014, p. 3-4)

Em (d), (e), (f) o (al-x)ex-escravo alfabetizado enumera as atividades como em (d) chorei no pez delle;não queria ser feitor/ele diz que escravo faz o que a senhoria manda;essasenunmerações têm como memorável a submissão em (e)dahi a cinco mez e comprou 6 escravo; 11 mes comprou 16 escravo;dahi a doze mez 28 escravo;essas enumerações têm o memorável do aumento no número de escravos; a partir do memorável do trabalho realizado como escravo, (al-x) ressignifica a quantia de trabalho que realizou. Posso dizer que essas enumerações no memorável do passado projetam os diferentes trabalhos realizados enquanto escravo na pertinência que perspectiva o pertencimento(GUIMARÃES,2002) a um pedaço de terra. O ex-escravo Felício está constituindo um percurso de memória como escravo do lugar social de ex-escravoalfabetizado no acontecimento de responder a um pedido ao bisneto do Conde do Pinhal. Aproveitemos para deslocar esse pedido constituindo-se numa resposta como resistência aos memoráveis numa perspectivação de denuncia em relação à quantidade de trabalho.

$\operatorname{Em}(\mathrm{g})$

(g) Eu fui companheiro de abrir a fazenda de seu pae, fui companheiro de abrir a fazenda Santo Antonio, fui companheiro de abrir o parmitara fazenda serra boa vista de ajudar criar 13 filhos trabalhei muito (ACERVO DA FAZENDA CONDE DO PINHAL.CARTA DO ESCRAVO FELÍCIO ID 3014, p.3-4)

$\mathrm{O}(\mathrm{al}-\mathrm{x})$ ex-escravo está constituindo um percurso de memória como escravo do lugar social de ex-escravo-alfabetizado no acontecimento de responder a um pedido ao bisneto do Conde do Pinhal

Especificamente em $(\mathrm{g})$, vejamos as enumerações em $(\mathrm{g})$

Eu fui companheiro de abrir a fazendo de seu pae fui companheiro de abrir a Fazenda Santo Antônio fui companheiro de abrir a Parmitar a fazenda serra boa vista 
Essas enumerações de atividades têm como memoráveis as construções dos bens que especificam os muitos trabalhos realizados pelo al-x-ex-escravo, são a quantia dos bens que o Conde do Pinhal construiu com a ajuda do escravizado.

Em (h)

(h) eu não esperava dessa ingratidão que me fizerãm dou graças a Deus Doutor Cristiano me dá um pedacinho de terra par esper que vocês socorancon alguma couza.(ACERVO DA FAZENDA CONDE DO PINHA.CARTA DO ESCRAVO FELÍCIO ID 3014, p.3-4)

A adjetivação ingratidão descreve o resultado dos trabalhos realizados pelo Alx-ex-escravo alfabetizado Essa adjetivação perspectivaum pedaço de terra na pertinência de que se resolva a situação, de que essa ingratidão seja resolvida com alguma coisa como em par esper que vocêssocorancon alguma couza

Essas atividades se integram para o ex-escravo afirmar seu pertencimento à terra. $\mathrm{O}$ ex-escravo nessa discursividade, o espaço enunciativo da liberdade, desloca o silenciamento do que foi ser escravo para a reivindicação da terra. Então, para o acervo da Fazenda Conde do Pinhal, o título da carta do escravo Felício dá-se pelo equívoco, uma vez que ele já estava em liberdade. Aí o sujeito se significa e "é nos modos de sua individualização que presidem seu processo de identificação". (ORLANDI, 2014, p. 78).

O liberto não fala mais do lugar de escravo. Assim, a carta ressignifica o escravo deslocando seu lugar para ex-escravo. Temos então um deslizamento de sentido nesse agenciamento enunciativo. Aqui a escrita de si nessa carta ressignifica o escravo, inaugurando um lugar de pertencimento a um pedaço de terra dos escravizadores. $\mathrm{O}$ modo de gerir administrativamente o silenciamento da voz do escravo na Fazenda Conde do Pinhal desconhece o deslocamento do lugar social. Isso tudo constitui a perspectivação que projeta, pela memória, um pertencimento a um pedaço de terra na atualidade. E a perspectivação para a futuridade seria a necessidade de redistribuição da terra da Fazenda Conde do Pinhal, já tombada patrimonialmente.

\section{REFERÊNCIAS}

DIAS, L.F. $O$ Adjetivo na Formação Nominal: uma abordagem enunciativa.

Universidade Estadual de Mato Grosso do Sul Ed.9, jan-maio, 2012.Disponível em: $<$ www.discursividade.cepad.net.br $>$.Acesso em: 30 out. 2016.

. Formações Nominais designativas da língua do Brasil: uma abordagem enunciativa. In: Língua, Museu e Patrimônio. Santa Maria,v.23, n.046,p.11-22, jan-jun 2013.

$O$ acontecimento enunciativo e formação sintática. Revista Língua e Instrumentos Linguísticos. Campinas, n. 35, 2015.

GUIMARÃES, E. Semântica do Acontecimento: um estudo enunciativo da designação. Campinas- SP, Pontes, 2002.

. Análise de Texto-Procedimentos, Análises, Ensino. Campinas-SP, Editora RG, 2011. 
. Argumentação e Argumentatividade: relações de alocução. Disponível em http://www.uehposol.ufscar.br. Acesso em: 16nov. 2017

ORLANDI, E. Parkour: corpo e espaço reescrevem o sujeito. In: Revista Língua e Instrumentos Linguísticos. Campinas-SP, nº 34-jul-dez, 2014.

SCHREIBER DA SILVA, S. M. Argumentação e Interdiscursividade: o sentido do "como se" na lei e na jurisprudência-o caso do concubinato. Porto Alegre, Mercado Aberto Edufscar, 1999.

Recebido em: junho de 2017.

Aprovado em: julho de 2017.

\section{Como citar este trabalho:}

SCHREIBER DA SILVA, S. M. Narratividade, memorável e perspectivação na carta do escravo Felício. Traços de linguagem, v. 1, n. 1, p. 39-44, 2017. 